\title{
Additives in Plastics Applications
}

\author{
Roberto V. Todesco* and Nadi Ergenc
}

\begin{abstract}
The use of light stabilizers, e.g. UV-absorbers (UVA) and Hindered Amine Light Stabilizers (HALS) in thermoplastic polymers is highlighted. Examples are shown of what can be achieved in natural outdoor weathering as well as in accelerated weathering devices with UVA, HALS, UVA/HALS combinations, HALS/ HALS combinations, and the latest NOR-HALS technology. Both thin and thick article applications are discussed for polyolefins and some selected engineering plastics.

Furthermore a new class of effect additives is shown, e.g. permanent antistatic additives and biocides, including bacteriostats, algaecides, and fungicides.
\end{abstract}

Keywords: Algaecides · Antimicrobials · Antistatic additives · Antistats · Biocides · Effect additives · Engineering plastics · Fungicides · HALS · Light stabilizers · Polyolefins · UV absorbers

\section{Light Stabilizers}

Exposure to sunlight and some artificial lights can have adverse effects on the useful life of polymers. UV radiation can break down the chemical bonds in a polymer. This process is called photodegradation and ultimately causes cracking, chalking, crazing, color changes, and the loss of physical properties such as impact strength, tensile strength, elongation, and other properties. To counteract these damaging effects on polymer performance, a broad range of ultraviolet light absorbers (UVA) and hindered amine light stabilizers (HALS), have been commercialized during the last decades to solve the degradation problems associated with exposure to sunlight [1][2].

These UV stabilizers have specifically been designed to fulfill the needs of different polymer applications, taking into account the kind of polymer (polyolefins or engineering plastic), the thickness of the final article (fibers, films or thick sections), and the presence of pigments [3-5].

In the following sections, several applications covering a variety of substrates and light stabilizers are highlighted.
${ }^{\star}$ Correspondence: Dr. R.V. Todesco

Ciba Specialty Chemicals Ltd

$\mathrm{R}-1038.5 .25$

$\mathrm{CH}-4002$ Basel

Tel.: +4161 6362948

Fax: +41616362694

E-Mail: roberto.todesco@cibasc.com

\subsection{Light Stabilization of Fibers}

\subsubsection{Polypropylene Fibers}

Polyolefin fibers are versatile, economical, durable, stain resistant, and lightweight. High-performance hindered amine light stabilizers have expanded the number of applications for which polyolefin fibers can be employed - carpeting and upholstery applications for home and business, in the latest automobiles, geotextiles, umbrellas, outdoor furniture, and a variety of non-woven applications.

Because of the high surface-to-volume ratio in fibers, it is critical to employ stabilizers with low volatility and high resistance to extraction. High molecular weight hindered amine light stabilizers (HALS), such as HALS 622, HALS 944, and HALS 119 have long been recognized as the standard of performance [3][4]. Listed below are the products which represent the latest in polyolefin fiber UV stabilization.

\section{HALS 783}

HALS 783 is a high molecular weight, high performance HALS. It delivers superb cost-performance benefits with a level of UV stability equal or superior to other high performance HALS (Fig. 1).

\section{Sample: 10 Denier, White Pigmented PP Fiber \\ Exposure: Allas Weather-Ometer Ci 65 (2) $65^{\circ} \mathrm{C}, 05 \mathrm{WWm}^{2}$ at $340 \mathrm{~nm}$ \\ Test Criterion: h to 50\% Retained Tensile Strength}

No Light Stabilizers

$0.3 \%$ HALS 622

$0.3 \%$ HALS 783

$0.3 \%$ HALS 944

$0.3 \%$ HALS 119

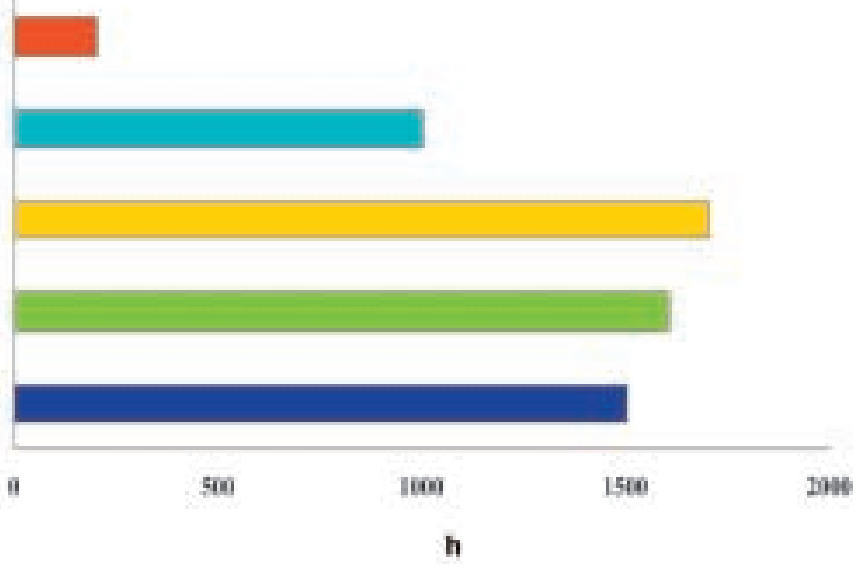

Fig. 1. Light stability of polypropylene fiber 


\section{HALS 2020 [6]}

HALS 2020 is a high molecular weight HALS with a narrow molecular weight distribution. It has virtually no effect on pigment color yield and little effect on polymer processing. HALS 2020 represents a continuing effort to bring the best performance and value in light protection. Fig. 2 and 3 show the superior performance of PP fiber stabilized with the new HALS.

Studies have shown that when HALS and pigments are present together in high concentrations, such as melt compounded in concentrates or masterbatches, color strength may be compromised. Examinations of test plaques with HALS and pigment concentrations under a microscope show the pigment to be less well dispersed, therefore yielding poorer color strength. HALS may either hinder the pigment dispersion or cause pigment agglomeration. However, this agglomeration is highly dependent on processing conditions (and not typically seen to this extent in production equipment).

New generation HALS such as HALS 2020 and HALS 119 eliminate this effect of pigment agglomeration. Therefore color yield is not affected by the HALS and is independent of the processing conditions. Table 1 compares the effects of these new generation HALS.

Table 1. Effects of HALS on color yield

\begin{tabular}{lr} 
HALS & Delta E (Ref. No HALS) \\
\hline HALS 2020 & $0.3-0.6$ \\
HALS 119 & $0.3-0.9$ \\
HALS 944 & $10.4-17.0$
\end{tabular}

$15 \%$ Flush of CPC Blue with 12.5\% HALS in PP, Brabender Mixed and Let Down 50/1 in PP.
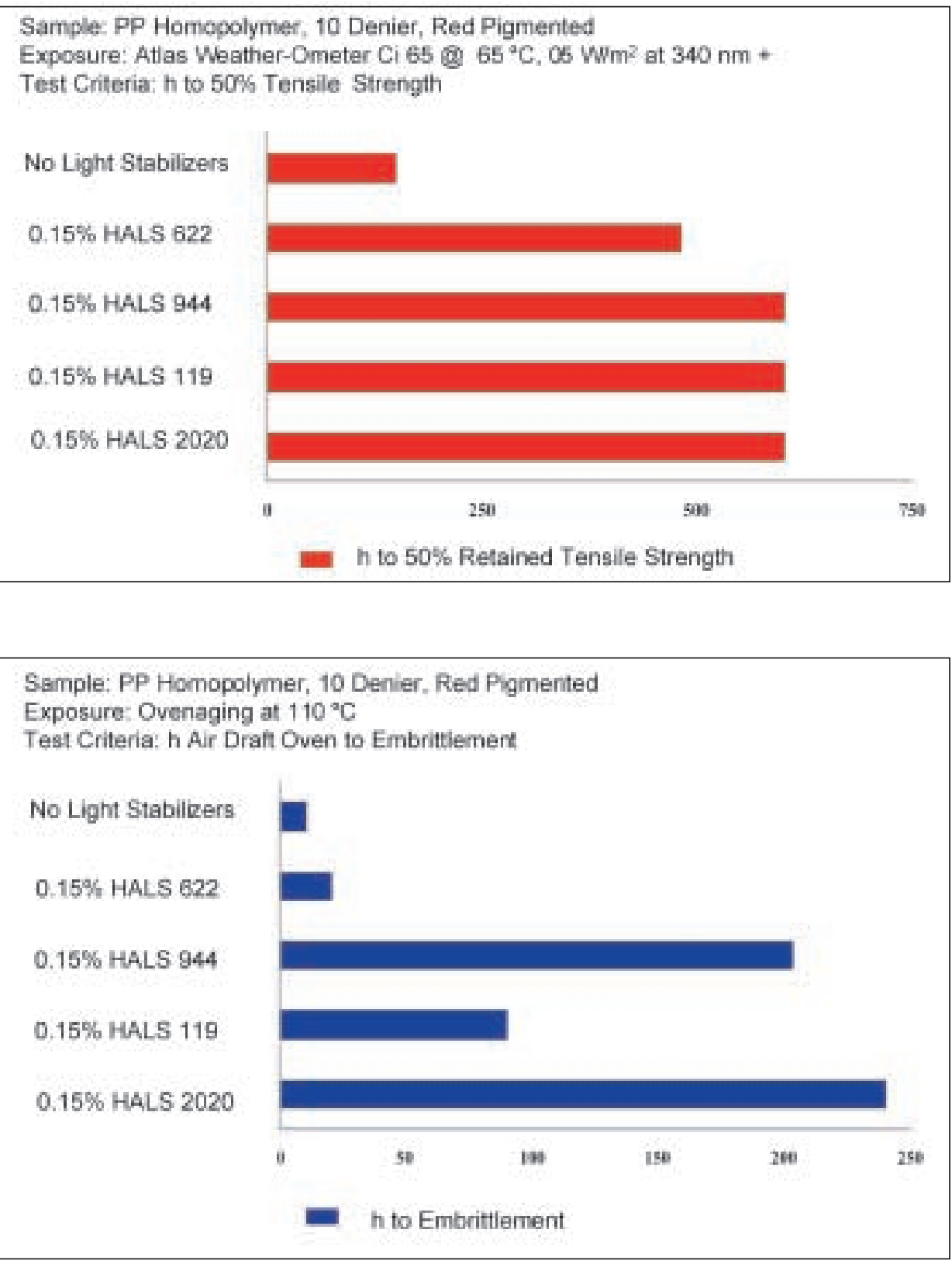

\subsubsection{Polyester Fibers [1]}

PET fibers are widely used in automotive interiors and outdoor applications. To be aesthetically pleasing, it is important that fibers remain strong and light-fast. UV absorbers improve the color stability and tensile properties when exposed to sunlight. Main applications are interior auto fabrics, e.g. seatbelts, sporting apparel, and outdoor fabrics (awnings, flags, etc.).

BZT 234 satisfies many of abovementioned UV application requirements. The premium UVA, HPT 1577, offers improved performance for harsher UV conditions (Fig. 4 and 5)

\subsection{Light Stabilization of Film}

In thin section applications, such as films, many factors need to be considered when selecting the right stabilization system for specific application require-
Fig. 2. Light stability of pigmented polypropylene fiber
Fig. 3. Thermal stability of pigmented polypropylene fiber 


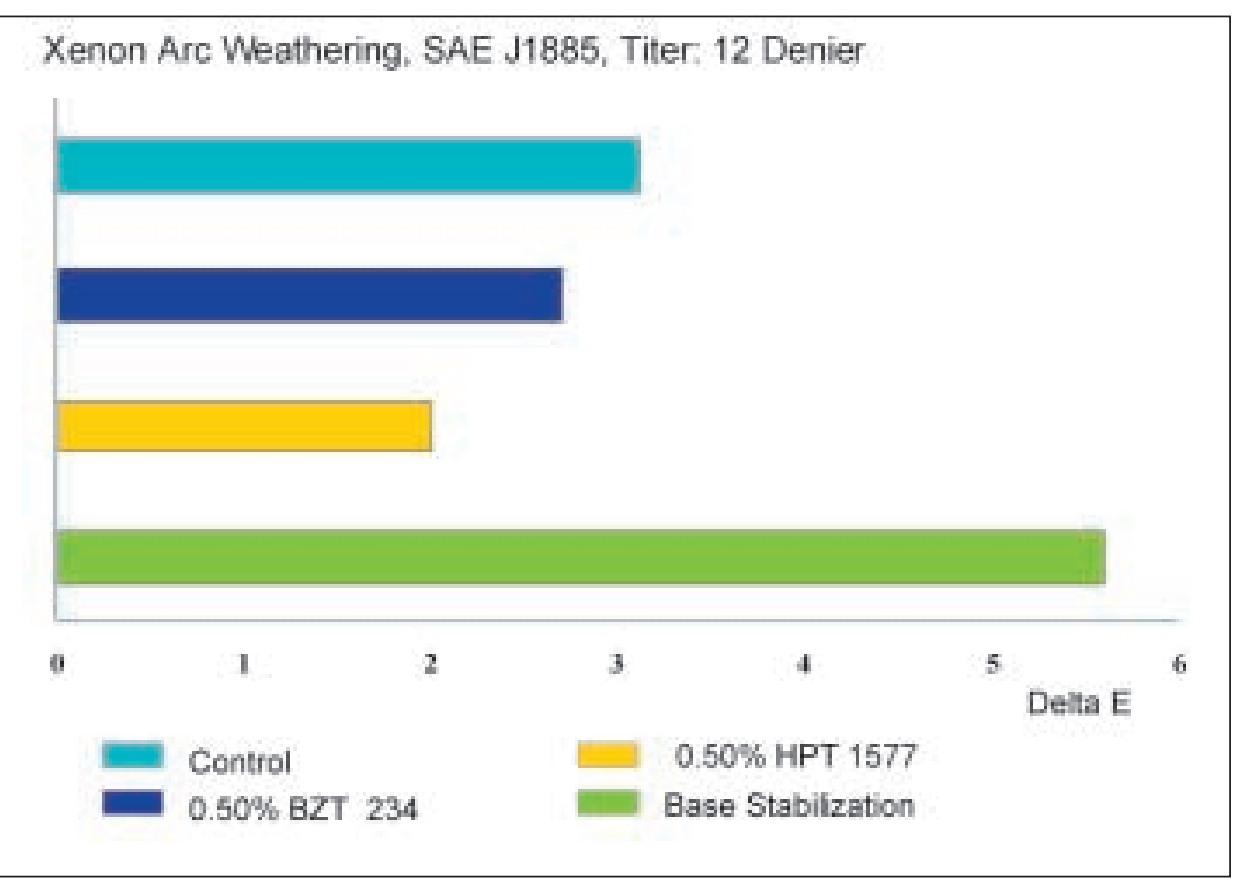

Fig. 4. Delta E values of natural PET fibers after $600 \mathrm{~kJ}$ light exposure

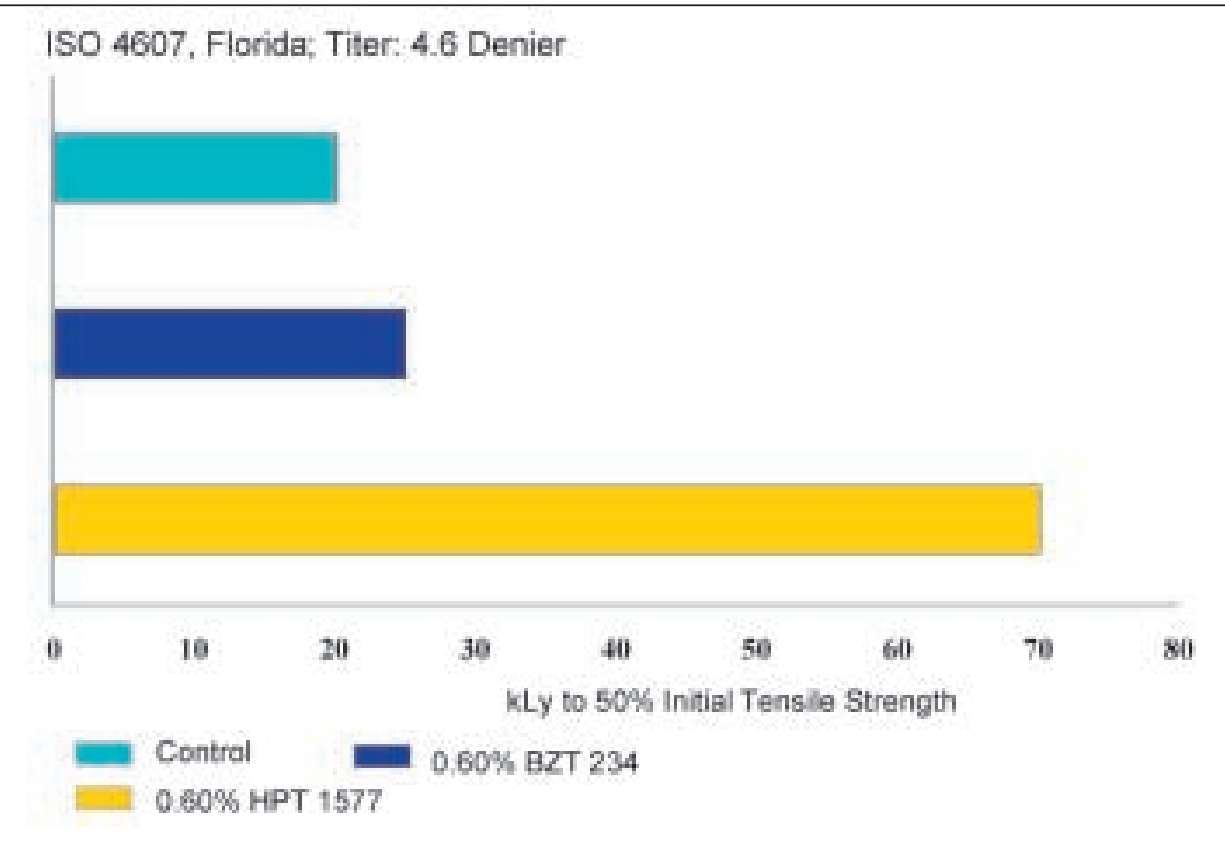

Fig. 5. Tensile strength of natural PET fibers after natural weathering

\begin{tabular}{llll} 
Light Stabilizer & & \multicolumn{2}{l}{$\mathrm{h}$ to $50 \%$ residual elong. } \\
\cline { 2 - 3 } & $150 \mu \mathrm{m}$ film & $100 \mu \mathrm{m}$ film & $50 \mu \mathrm{m}$ film \\
No Stabilizer & 650 & 600 & 500 \\
HALS 622+BZP 81 & 4500 & 4000 & 3000 \\
Concentration & $(0.15 \%+0.075 \%)$ & $(0.2 \%+0.1 \%)$ & $(0.3 \%+0.15)$ \\
HALS 783 & 7500 & 7000 & 5500 \\
Concentration & $(0.15 \%)$ & $(0.2 \%)$ & $(0.3 \%)$
\end{tabular}

ments. These include not only the resin/ additive formulation but also other parameters such as processing conditions, presence of mineral fillers and pigments, film thickness and construction, and the final application environment.

Table 2 illustrates the influence of film down-gauging (150-50 micron) on the selection of the stabilizer concentration. The lifetime of the film is decreased by decreasing the film thickness from 150 to 50 micron, even if the concentration of the stabilizers is doubled. Thus an adjustment of the additive concentration is needed to retain the same durability properties when the film thickness is reduced.

The bulk of LDPE, LLDPE, and EVA is used in the manufacture of films for packaging, agricultural and construction applications. Agricultural films used for greenhouse covering, mulching and silage wraps represent the largest light-stabilized PE and EVA applications.

\subsubsection{Construction and Industrial Film}

Construction and industrial films used outdoors for extended periods of time, ranging from some months to a few years, require proper UV light protection in order to meet end-users' requirements. Common applications are stretch films, shrink wraps, heavy-duty bags, and pool covers.

\section{HALS 783}

HALS 783 is widely used for LDPE, LLDPE and EVA films and has extensive indirect food contact clearances worldwide. It is an effective and versatile light and thermal stabilizer for films and delivers excellent cost/performance benefits. Fig. 6 demonstrates that HALS 783 provides superior UV stability in LDPE film compared to HALS 944 and HALS 622.

\subsubsection{Agricultural Film [7-9] Greenhouse and Small-tunnel Films}

The importance of greenhouse and small-tunnel films is documented by the estimated 500000 hectares of land given over to protected cultivation worldwide. This application can be particularly

Table 2. Influence of stabilizer concentration and film thickness on light stabilization of low density polyethylene film Sample: LDPE Blown Film Exposure: Atlas Weather-Ometer Ci $65 @ 65^{\circ} \mathrm{C}$; $0.35 \mathrm{~W} / \mathrm{m}^{2}$ at $340 \mathrm{~nm}$ 


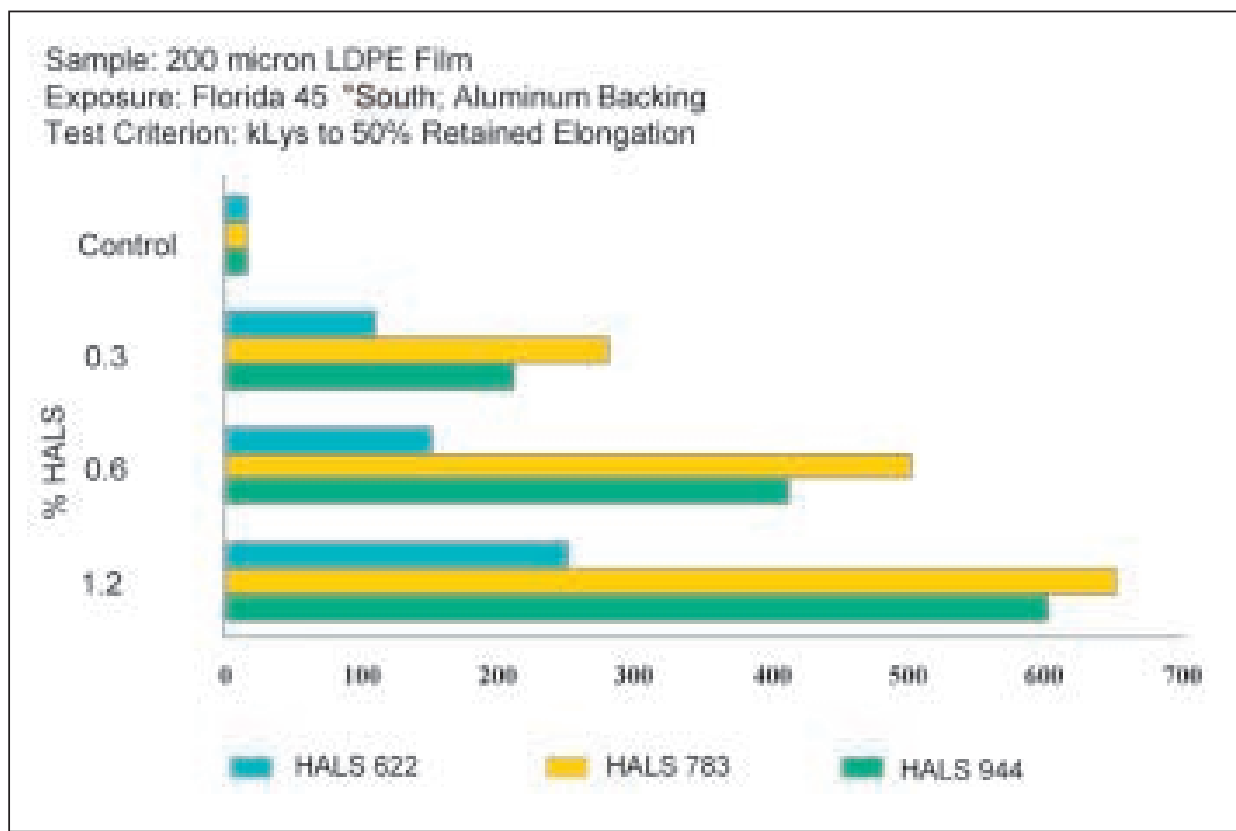

Fig. 6. Light stability of low density polyethylene film

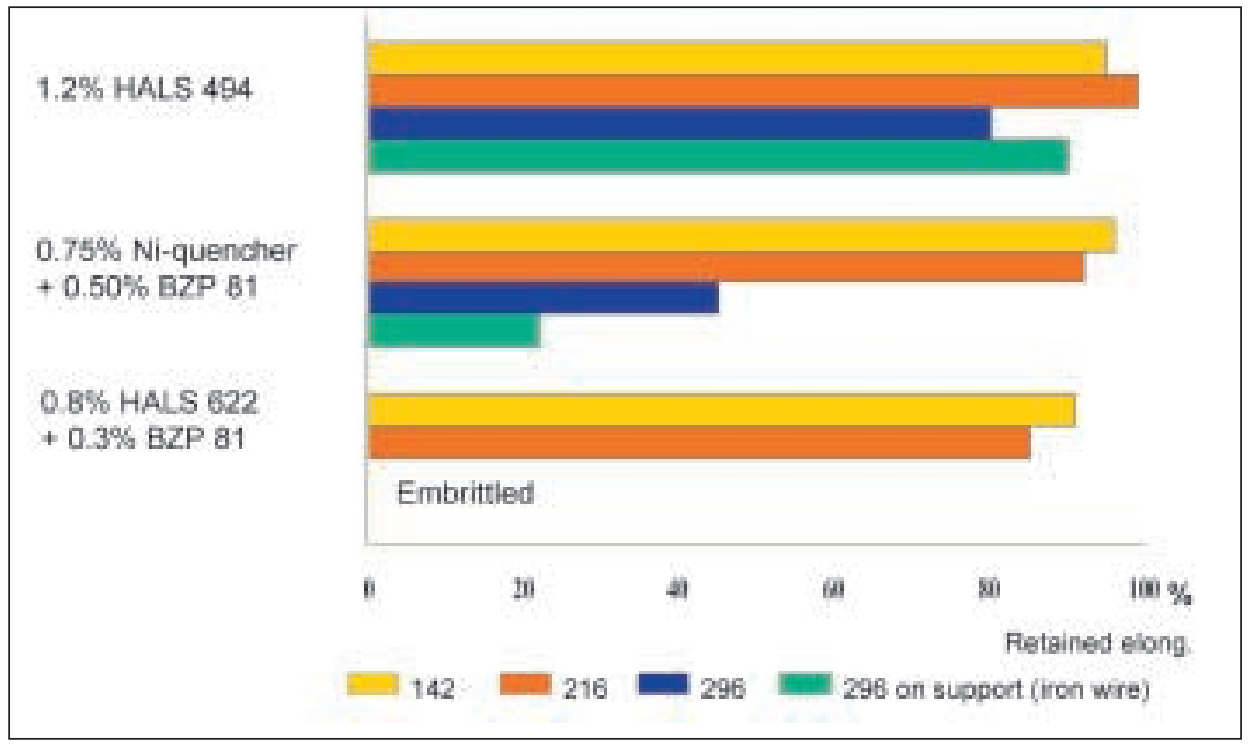

Fig. 7. Performance of LDPE blown films $(200 \mu \mathrm{m})$. Greenhouse exposure in Almeria, Spain (approx. $150 \mathrm{kLys} / \mathrm{yr}$ )

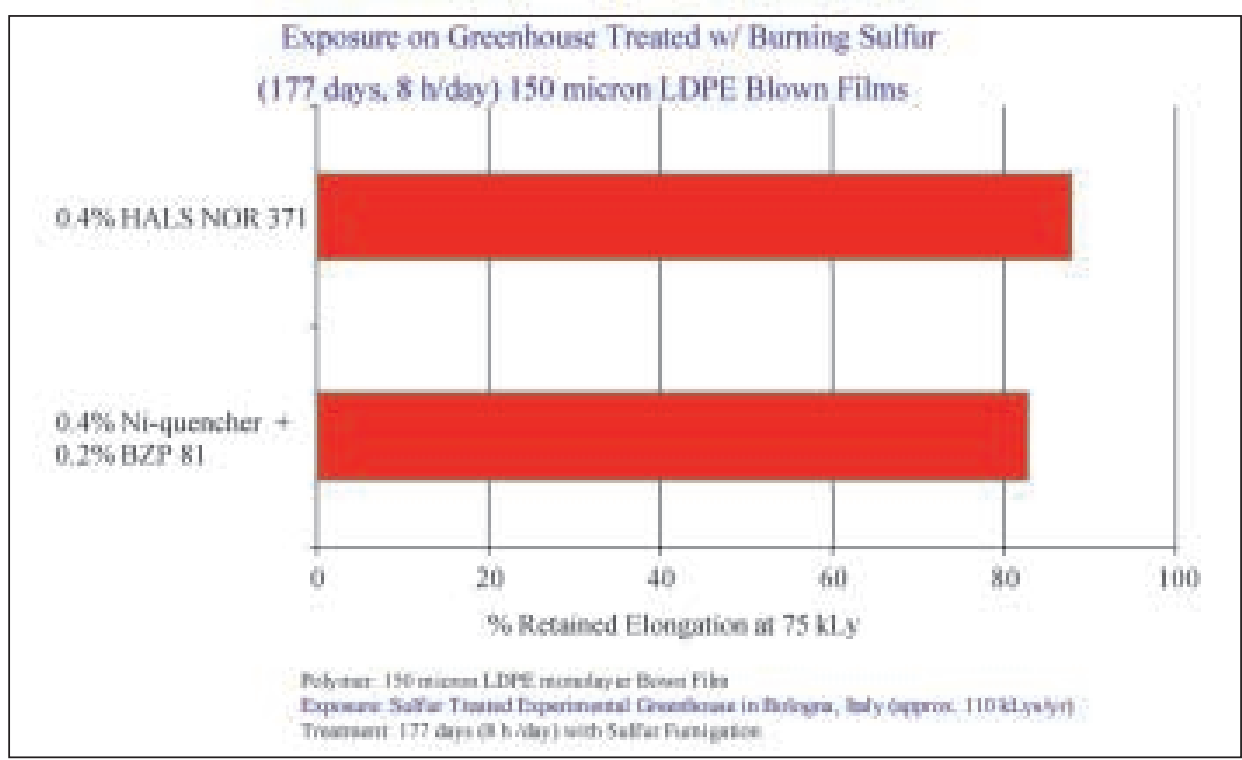

critical for polyethylene films (LDPE, LLDPE, EVA, EBA) due, among others, to high ultraviolet (UV) radiation exposure, heat build-up on the greenhouse support, and the effect of crop protection and soil disinfection chemicals that are extensively used in agriculture. These chemicals and the products of their decomposition can affect the long-term properties of the films and attack stabilizers.

The extent of this interaction depends on many parameters, like the types of chemicals used, frequency of treatments, types of crops, temperature, and humidity, etc., and is thus very difficult to predict. This explains why the requirement of chemical resistance for greenhouse film stabilizers is, in many cases, compulsory.

\section{HALS 494}

HALS 494 is a state-of-the-art thermal and light stabilizer for greenhouse long-life films. EVA, LDPE, LLDPE, and EBA films containing this additive have shown outstanding resistance to the effect of solar irradiation and to the thermal effect of supports (e.g. wood, galvanized iron, aluminum) in every lab and field test. This is combined with very good resistance to the traditional soil disinfection and crop protection chemicals normally applied in agriculture.

The results of a greenhouse exposure trial carried out in Almeria, Spain, using LDPE films stabilized with HALS 494 fully support the excellent performance claims compared with other traditional light stabilizers used in the area (Fig. 7). The results are especially important in view of the very critical climatic conditions (high irradiation, high temperature, strong wind) and the extensive use of agrochemicals. In addition, in contrast to others, films stabilized with HALS 494 show good long-term retention of mechanical properties on the full film as well as in contact with the iron wire supports.

\section{NOR-HALS}

The newest development in the field of stabilization of greenhouse films is the use of NOR-HALS, which are particularly effective when used in harsh conditions, like treatment with burning sulfur. Fig. 8 clearly illustrates the very good performance of a film stabilized with NOR-HALS.

Fig. 8. UV stability in sulfur-treated greenhouses 


\subsection{Light Stabilization of Molded Applications}

Thick section polyolefins are widely used in a variety of outdoor products such as house sidings, window shutters, stadium seats, garden furniture, trash cans, bottle and fruit crates, toys, and interior and exterior automotive parts and many more.

For many years, polypropylene and polyethylene were stabilized against the detrimental effects of UV radiation using a low molecular weight HALS such as HALS 770. During the mid to late eighties combinations of high molecular weight HALS with low molecular weight HALS provided a better balance of UV stability, thermal stability and substrate compatibility. Some of the newest products for thick section polyolefins include HALS 123, a non-interacting, low molecular weight NOR HALS; HALS 2020, a low volatility, oligomeric high performance HALS; HALS 783 and HALS 791, new HALS that exploit mixed HALS synergy; and Phenolfree FS 210, Phenolfree FS 410, Phenolfree FS 811 and Phenolfree FS 812, a family of phenolfree stabilizers that perform best in color critical applications.

\subsubsection{Polypropylene for Automotive Application [10]}

Polypropylene homopolymers and copolymers for automotive applications have traditionally been stabilized with a combination of hindered phenolic/hindered phosphite process stabilizer and the hindered amine light stabilizer HALS 770 .

\section{HALS 791}

Recent studies show HALS 791 provides better light stability and highly improved thermal stability compared to HALS 770 (Fig. 9 and 10). In organic pigmented applications, the addition of a benzotriazole ultraviolet absorber enhances light stability and helps prevent the pigment from fading (Fig.11).

Phenolfree FS 210, Phenolfree FS 410, Phenolfree FS 811, Phenolfree FS 812

Molded-in color polypropylene and impact modified polypropylene is replac-

Fig. 11. Typical physical property of polypropylene copolymer plaques

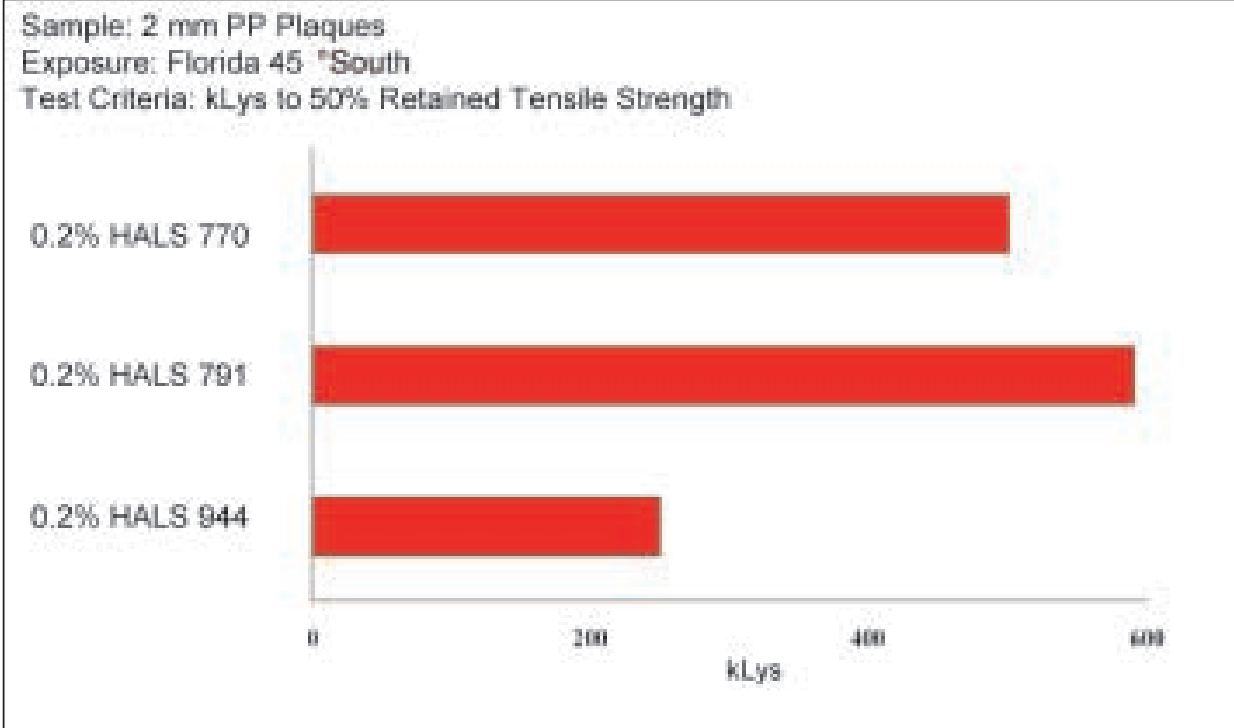

Fig. 9. Light stability of polypropylene plaques

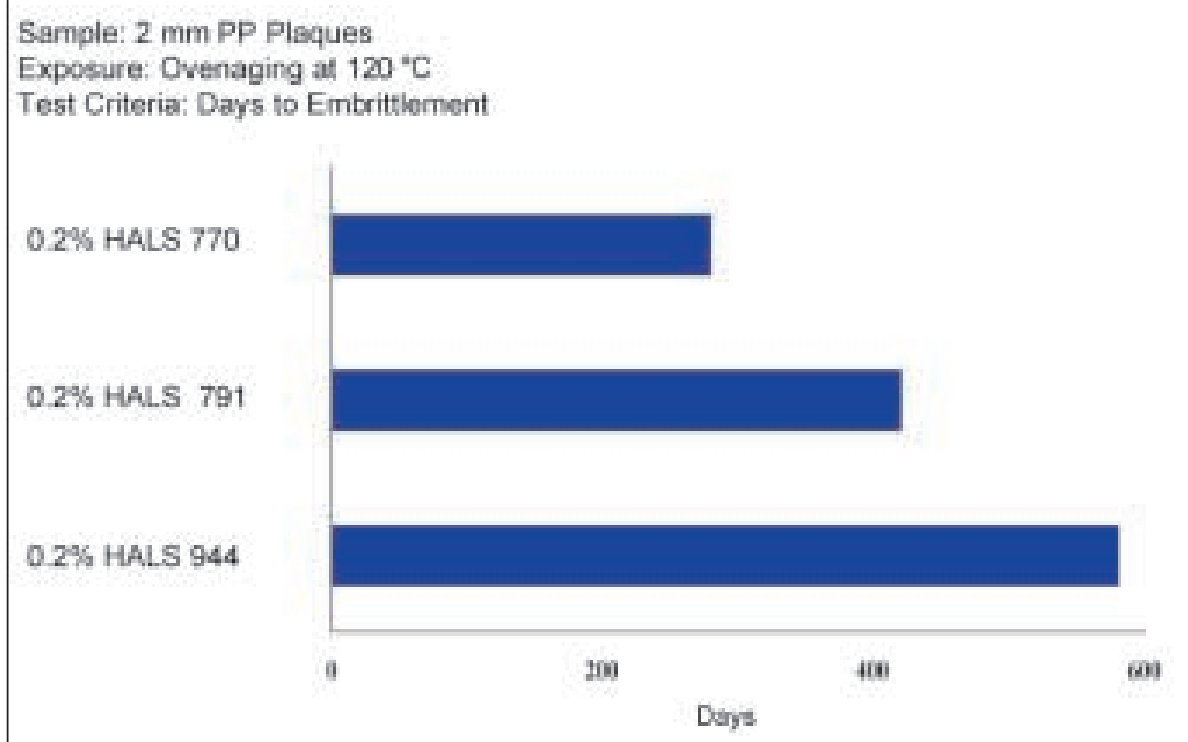

Fig. 10. Thermal stability of polypropylene plaques

Sample: 2 mm PP Copolymer Plaques

Exposure: Florida $45^{\circ}$ South

Test Criterion: Increase in kLys to Surface Roughness

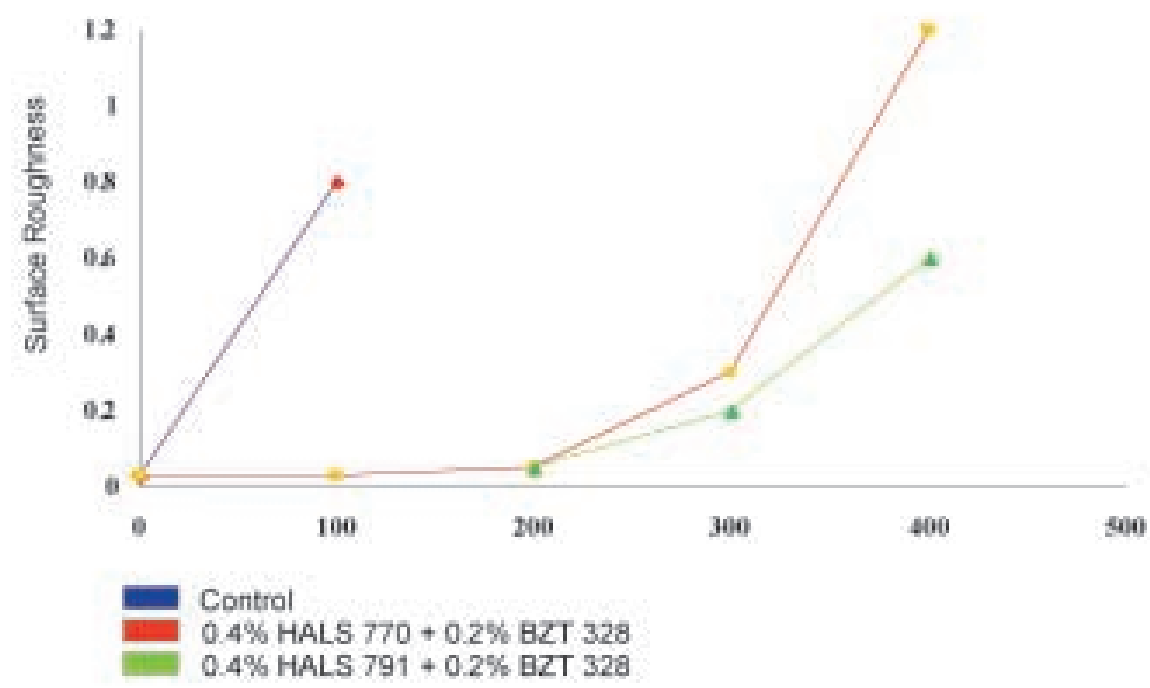


ing painted plastics in applications such as auto bumpers and interior and exterior trim. Recently a family of phenol-free stabilizer systems has been developed for these color critical applications. These phenol-free stabilizer systems are based on a new alkyl hydroxylamine process stabilizer that helps achieve good process stability while also obtaining excellent initial color, color consistency, and color maintenance during end use. Examples of phenol-free stabilizer systems include Phenolfree FS 210, Phenolfree FS 410, Phenolfree FS 811, and Phenolfree FS 812. Table 3 shows that Phenolfree FS 812 can provide dramatic improvement in light stability. In addition, using a phenol-free stabilizer system such as Phenolfree FS 812 virtually eliminates gas fade discoloration, a phenomena that typically leads to a yellowing, pinking, or off-shade discoloration of articles stored in warehouses.

\section{HALS 123}

Car manufacturers strive to produce automobiles that will look and perform well for ten years. For aesthetic and styling reasons, manufacturers often partially paint molded-in color polypropylene. Thus light stabilizers must provide longterm stability and must not interfere with the adhesion of coatings to the substrate. HALS 123, a new non-interacting NOR HALS, helps polypropylene producers achieve both outstanding long-term light stability and good adhesion to TPO surfaces. Fig. 12 shows the dramatic protection this high-performance system provides in a molded-in color red pigmented TPO composition compared to a traditional phenolic system containing HALS 791.

\subsubsection{Construction/Architectural Applications \\ HALS 123}

The low basicity and non-interacting nature of HALS 123 allows it to function well in acidic environments such as applications containing halogenated flame retardants.

HALS 123 is uniquely suited to protect flame-retardant roofing and stadium seats from UV deterioration. These extremely demanding end uses require the most advanced, highest performing light-stabilizer systems available. Fig. 13 shows that a phenolic-free stabilizer system containing HALS 123 with HALS 2020 allows a blue pigmented TPO composition to maintain more than $50 \%$ of its initial gloss even after $7,000 \mathrm{~kJ}$ of weathering in an Atlas Weather-Ometer.
Table 3. Xenon weathering of molded-in color TPO (PP/EPDM)

\begin{tabular}{lllll}
$\begin{array}{l}\text { UV stabilizer } \\
\text { system }\end{array}$ & $\begin{array}{l}\text { Red pigmented } \\
\text { kJ to onset of } \\
\text { chalking }\end{array}$ & $\begin{array}{l}\text { TPO } \\
\text { Delta E at 2500 kJ }\end{array}$ & $\begin{array}{l}\text { Blue pigmented } \\
\text { kJ to onset of } \\
\text { chalking }\end{array}$ & $\begin{array}{l}\text { TPO } \\
\text { Delta E at 2500 kJ }\end{array}$ \\
$\begin{array}{l}0.1 \% \text { Base } \\
\text { stabilization / + }\end{array}$ & 1250 & 58.4 & 1920 & 22.5 \\
$\begin{array}{l}0.4 \% \text { HALS 791 } \\
+0.2 \% \text { BZT } 328\end{array}$ & & & \\
\hline $\begin{array}{l}0.65 \% \text { Phenolfree } 4000 \\
\text { FS 812 }\end{array}$ & 4.2 & $>4000$ & 1.8 \\
\hline
\end{tabular}

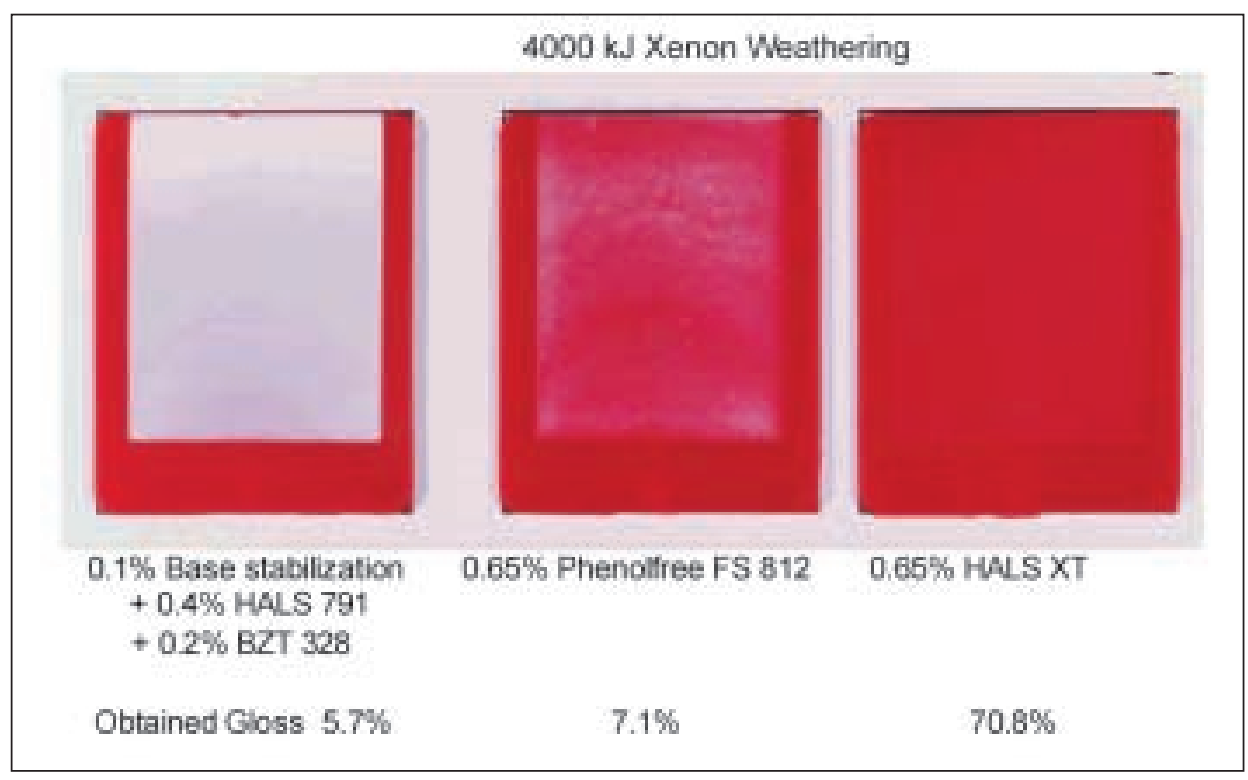

Fig. 12. UV stability of TPO (PP/EPDM)

\section{Pigmentation: $1.6 \%$ Mixed Blue Pigment \\ Exposure: $7000 \mathrm{~kJ}$ Atlas Weather-Ometer (SAE J 1960) \\ Test Criterion: \% Gloss Retention}

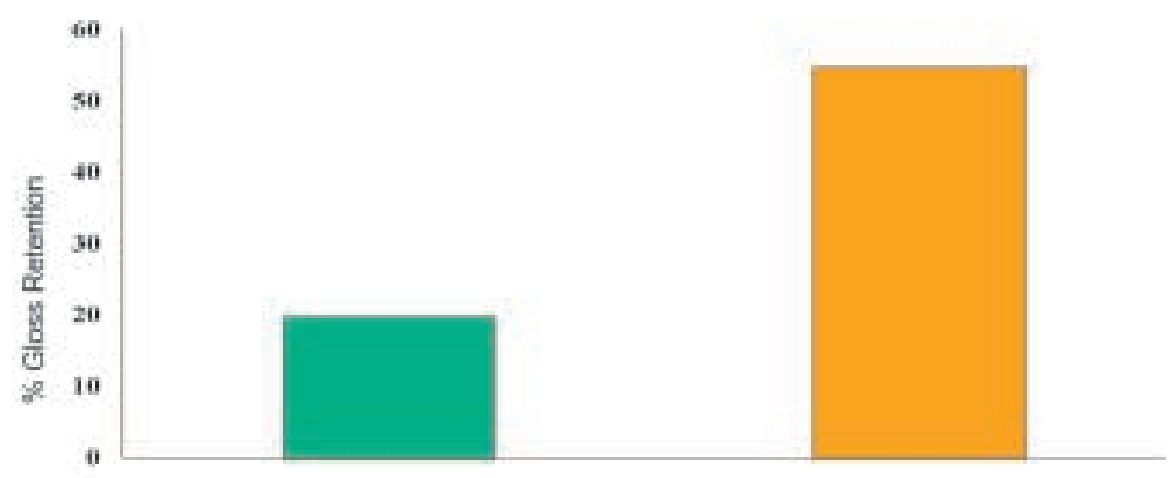

$0.1 \%$ Base stabilization $+0.4 \%$ HALS $791+0.2 \%$ B2T 328 $0.65 \%$ HALS XT

Fig. 13. Light stability of blue pigmented TPO (PP/plastomer) 
The performance of these novel light stabilizer systems has allowed polyolefin producers to enter markets previously dominated by engineering polymers or other non-plastic materials. They have also allowed manufacturers of polyolefin roofing, siding and window shutters to offer consumers extended warranties against failures due to premature weathering.

\section{Effect Additives}

In this section the benefits and values special effect additives can add to polymer products are discussed. Several examples illustrate the concept of maximizing the value to end-users.

Benefits of antimicrobials and permanent antistatic additives, with main focus on biocides, are discussed.

\subsection{Antistatic Additives [11-13]}

Polymers in general and polyolefins in particular are known for their ability to accumulate electrostatic charges. This is a result of their low electrical conductivity (surface resistivity in the order of $10^{15}$ to $10^{17} \Omega$ ). They acquire electrostatic charges mostly by friction with another non-conductive media. The tendency of materials to gain or lose charge can be related to their molecular structure and falls onto a scale called the triboelectric series. Most plastic materials are on the negative end of the scale, thus tending to gain electrons. Sweeping dry air can suffice to cause electric charges on polymer surfaces to accumulate, which then easily attract dust particles present in the atmosphere. While dust pick-up is mostly an aesthetic issue, electric charges can cause other more severe problems. This includes explosions caused by sparks or electrostatic discharge that leads to damages of electronic parts. The cost of fail-

Fig. 14. Charge transfer over time: steep and narrow for conductive materials (blue), flat and spread for static dissipative material (brown) ure in these cases can be very high and the value of products that reduce or eliminate the potential of occurrence is accordingly high. The choice of antistatic additives has to take this fact into account. Examples of potential undesired effects that electrostatic charges can have are for instance:

- Solids build-up on walls of plastic containers during filling process

- Fouling caused during pneumatic conveying of pellets

- Destruction of electronic parts

- Ignition of vapors or dust

- Attraction of dust

- Clinging effects during fabrication or conversion of sheets or fibers

In an attempt to address the problem of electrostatic charges several solutions have emerged over time. These include topically applied antistatic additives, carbon black and other conductive fillers, intrinsically conductive polymers, and classical migratory systems such as glycerol monostearates and ethoxylated amines. Here, we will focus on products belonging to the intrinsically conductive polymers and the classical migratory additives. Both of these product categories provide static dissipative properties as opposed to conductive characteristics like in the case of carbon black. There is a fundamental difference between static dissipative and conductive properties in the way the products release charge and thus energy over time. Polymers with surface resistivities up to $10^{7} \Omega$ are considered conductive and products with surface resistivities between $10^{8}$ to $10^{12} \Omega$ are static dissipative.

Conductive materials have to be grounded to avoid sparks caused by instant release of electric energy. In the case of dissipative materials, removal of electrical charge is spread over time with a significantly reduced amplitude thus reducing the overall potential for severe damage. It is known that charges of about $30 \mathrm{nC}$ can ignite an ethylene/air mixture. Charge decay behavior depends on the system that is chosen but the key is reduction of the amplitude in order to avoid charge related damages. Dissipation of electric charge over time is schematically illustrated in Fig. 14. Charge decay behavior of polymers is gaining in importance since it is recognized by the industry that surface resistivities will not give sufficient information on residual risk associated with electric charge.

\subsubsection{Migratory Classical Antistats}

The classical migratory systems typically have a lipophilic tail and a hydrophilic head. These materials are chosen to be sufficiently incompatible with the polymer matrix so that they migrate to the surface. Once at the surface, the hydrophilic head adsorbs moisture from the air and provides a layer that gives the polymer a static dissipative surface. This type of product does not show any capability to dissipate electric charge from the bulk or in other words these products are insulative with respect to volume resistivity.

These classical antistats have the following characteristics:

- Effective below 2\% loading

- Require about 50\% relative humidity

- Require induction period before becoming effective

- Non-permanent and can be washed off

- May negatively impact paintability and printability.

- Products may cause plate out onto equipment surfaces

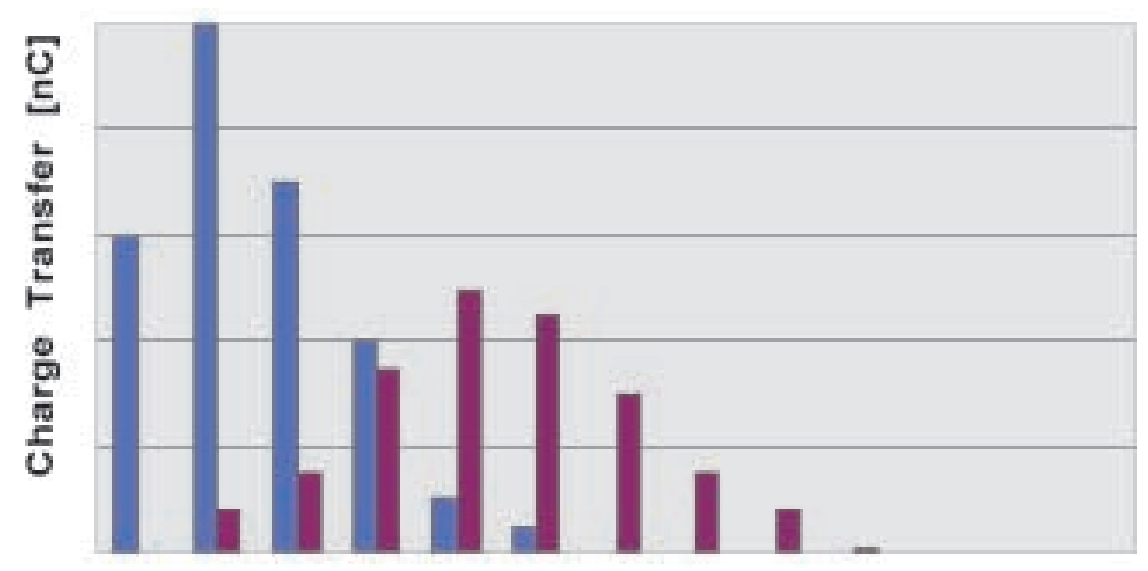

Time [s] 
There is a trade-off to be made in the selection of these antistats between the time it takes to establish the antistatic effect and durability of the antistatic effect. Blends of several products will usually yield the most effective balance of properties. Some examples of conventional antistatic systems are shown in Fig. 15 and 16. Notice how the blend of Antistat AS290G outperforms neat ethoxylated amine Antistat 261 in both the surface resistivity test as well as the more sensitive static decay time test.

The fact that migratory systems depend on humidity to be effective is not acceptable in a variety of applications such as packaging for electronics or when it comes to applications where safety is at stake. The temporary effect of these additives make them suitable for applications either with a useful life of less than one year or for the purpose of enhancing manufacturing processes. Main applications include consumer goods packaging for dust pick-up prevention. The use of antistatic additives for enhancement of processes include for example the manufacture of films or the manufacture of expandable polyolefins in particular when flammable blowing agents are used. Antistat AS290G is a good example of a universally usable antistatic additive suitable for all polyolefins and a variety of other polymers. The product has an additional benefit of significantly reducing the coefficient of friction (CoF) making it particularly suitable for the manufacture of films.
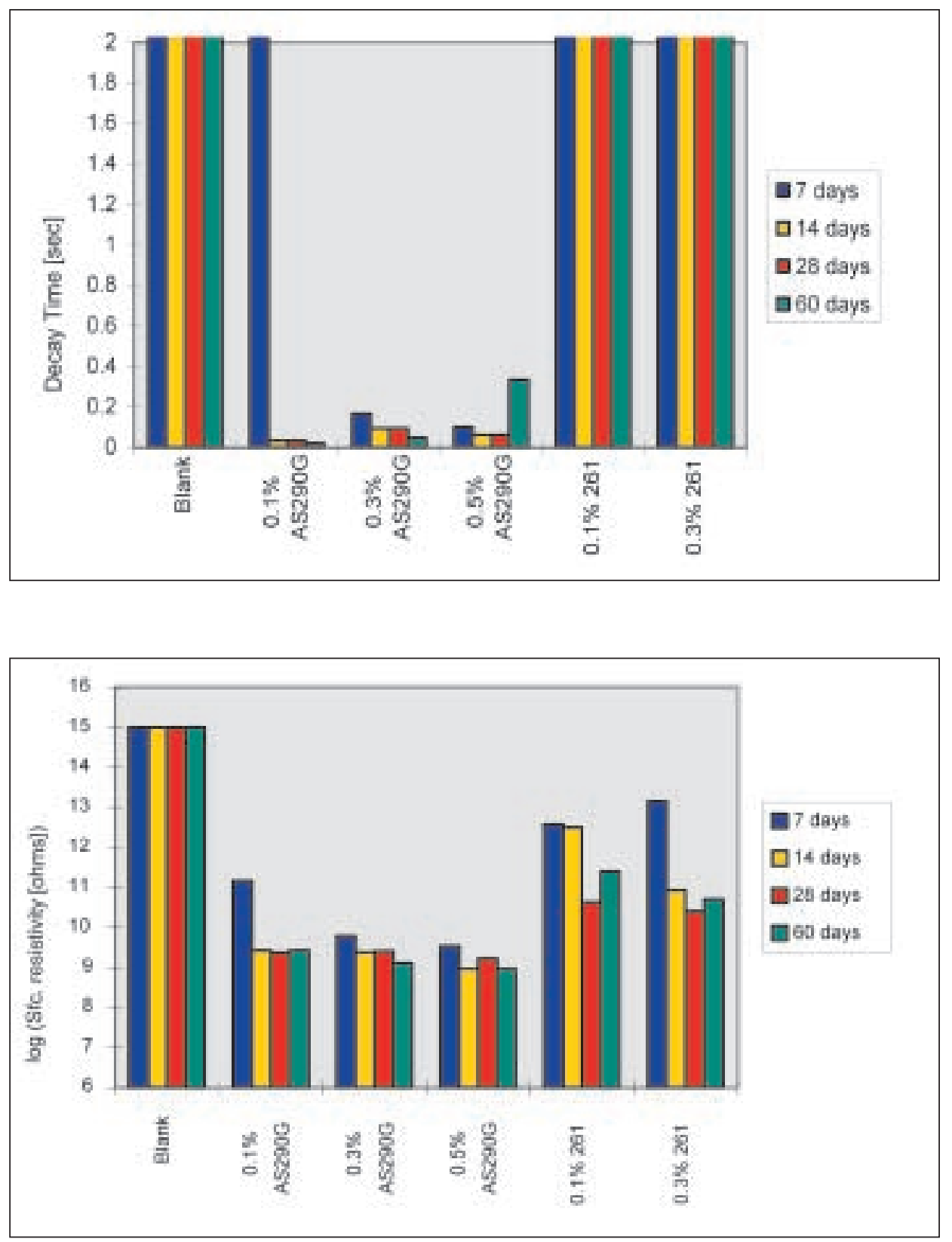

Classical antistatic additives do not show volume conductivity because a static dissipative layer of water is developed only on the surface. Applications that do not allow any of the limitations associated with migratory systems require the use of permanent solutions.

\subsubsection{Permanent Antistatic Additives [13]}

The following products fall under the category of permanent systems:

- Intrinsically conductive polymers (hydrophilic copolymers)

- Conductive polymers (polyanilines)

- Conductive fillers like carbon black

All these solutions have drawbacks. Conductive polymers and carbon black are strongly colored. Hydrophilic polymers may have to be added at high levels
Fig. 15. Static decay time for EP copolymer films; $50 \%$ rh, $20{ }^{\circ} \mathrm{C}$; Antistat AS290G and Antistat 261 vs. blank
Fig. 16. Surface resistivity for EP copolymer films; $50 \%$ rh, $20^{\circ} \mathrm{C}$; Antistat AS290G and Antistat 261 vs. blank 
to polyolefins (up to $30 \%$ ) to show the desired effect, negatively influencing the properties of the final article. Carbon black materials are conductive as opposed to static dissipative which can mean a major drawback.

Recently a permanent antistatic agent Antistat $\mathrm{P}$ has been introduced in the polymer market. The new system is colorless and provides static dissipative properties at loadings of 5-15\%. Antistat P 22 can be used at processing temperatures above $220{ }^{\circ} \mathrm{C}$ and Antistat P 18 at temperatures above $180{ }^{\circ} \mathrm{C}$. Antistat $\mathrm{P}$ is a combination of an intrinsically conductive material and polyamide.

The novelty about this new system is its fiber-forming characteristics allowing for the development of a percolating conductive network within the polymer matrix. The fiber structure, compared to a dispersed system, explains the fact that much less of the antistat is required for obtaining the same level of activity.

Edging technology on a Antistat P-containing sample allowed the visualization of the network under the microscope (Fig. 17). The diameter of these fibers are in the range of $0.2-15 \mu \mathrm{m}$, several orders of magnitudes smaller than the length of the fibers.

To allow the network to develop, Antistat $\mathrm{P}$ has to be completely molten and exposed to sufficient shear during processing of the material.

The five key advantages of Antistat P can be summarized as follows:

- Effect independent of relative

humidity (Fig. 18)

- No adverse effect on mechanical properties

- Permanent effect (Fig. 19)

- No impact on color nor transparency

- Exhibits volume conductivity and thus excellent charge decay times

The use of this type of antistatic system as opposed to the use of systems such as Antistat 290 G strongly depends on the application requirement or in other words the value in use. The use of Antistat $P$ is suited for electronic and industrial packaging, electronic housings and polymer supplies that are used in hazardous environments aiming at reducing the risk of formation of destructive sparks.

Fig. 19. Antistat $P 22$ in PP injection molding. $50 \% \mathrm{rh}, 20^{\circ} \mathrm{C}$; time 0 immediately after processing

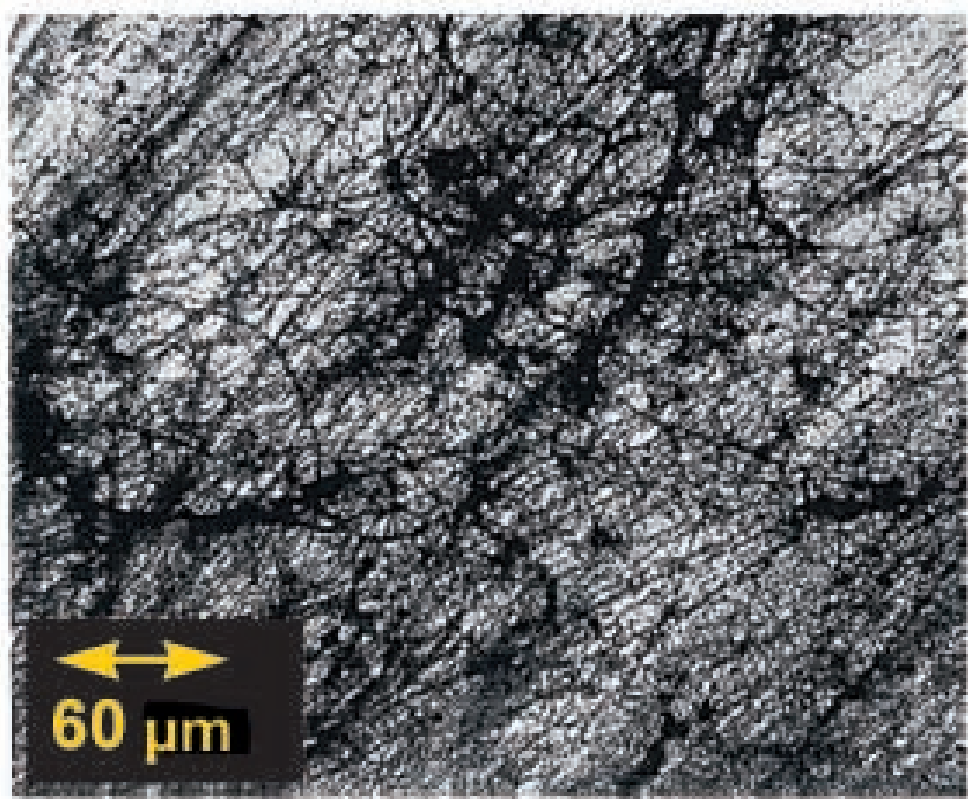

Fig. 17. Photomicrograph showing the structure of the conductive network

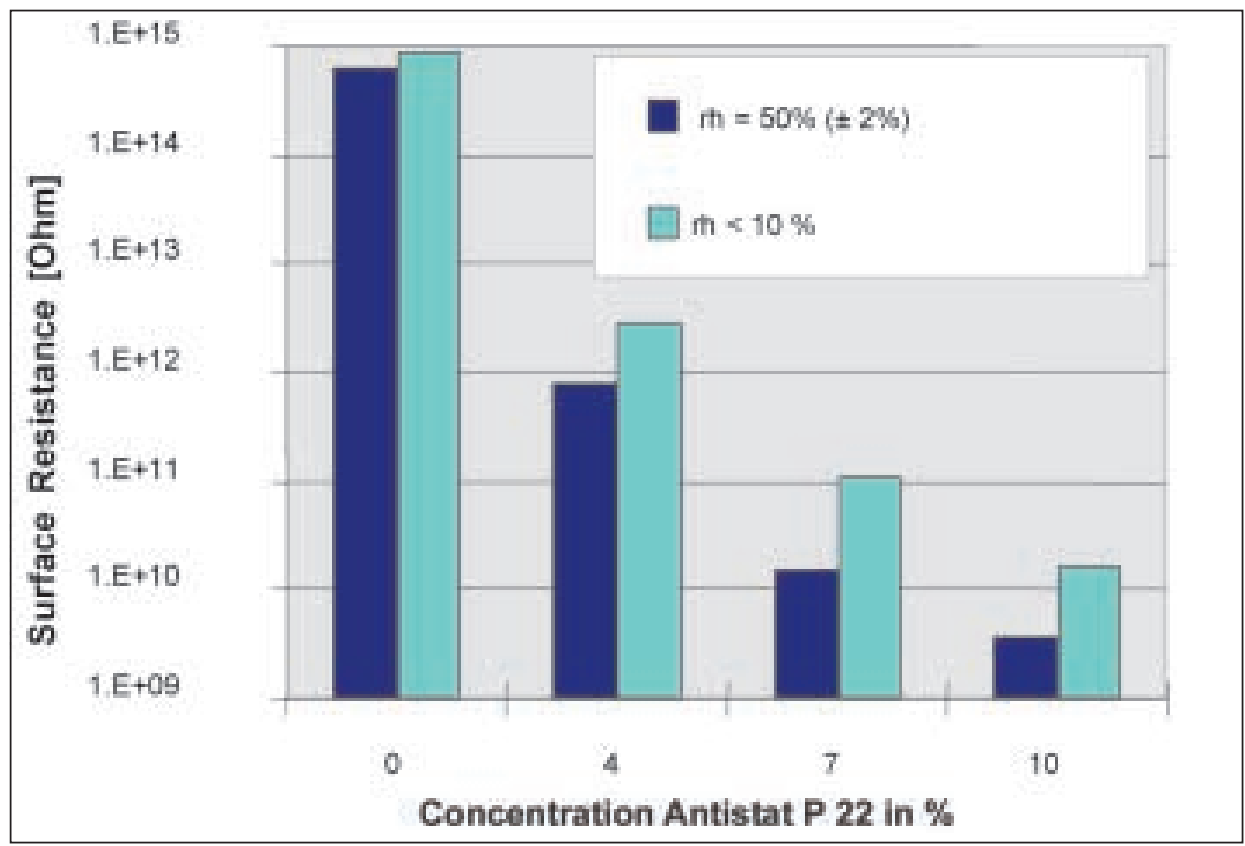

Fig. 18. Antistat P 22 in PP injection molding. Surface resistance electrode $\{8 \mathrm{~cm}$

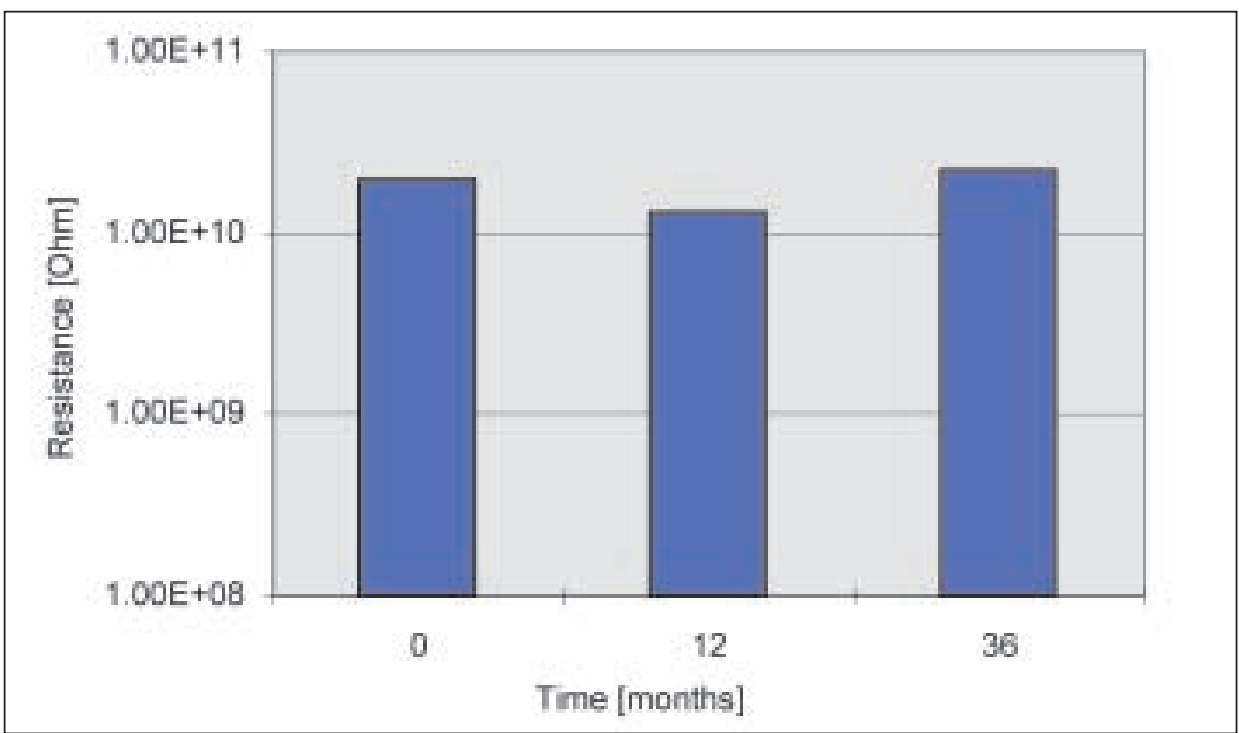




\subsection{Biocides [14][15]}

The biocide concept is based on solutions that provide active built-in protection against growth of algae (Biocide $\mathrm{A}$ ), bacteria (Biocide B) and fungi (Biocide F). Only a few years ago Biocide B, a highly effective bacteriostat which works in most thermoplastic polymer applications, has been commercially introduced. Recently Biocide A, an algaecide that shows high efficacy against growth of algae and moss was launched for polymers applications. Build-in protection supports inhibition of microbial growth which otherwise can occur in micro cracks on polymer surfaces (Fig. 20).

The benefit of having antimicrobial additives that provide activity from inside to the outside is effective inhibition of microbial growth on the surface and in micro cracks of polymers. The overall value for the application includes enhancement of:

- Productivity

- Hygiene

- Comfort

- Appearance

- Safety

Understanding the full value that such solutions can bring to the application is challenging and for this reason several practical examples are discussed.

Prior to exploration of the value, the benefit of using such additives has to be demonstrated and it is therefore a prerequisite to clearly demonstrate efficacy of the additive in the final application. For bacteria, algae, and fungi different test methods are meaningful.
The most commonly used method to show efficacy against bacteria is the agar diffusion test (Fig. 21).

To determine algaecidal effects either qualitative agar dish evaluations or field tests are feasible (Fig. 22).

To quantify activity against fungal growth, counts of colony-forming units is the only method providing meaningful results (Fig. 23).

\subsubsection{Practical Examples \\ Air Scrubbing System}

The first example illustrates the benefit of antimicrobial polypropylene packing material used in a vent air scrubbing system.

In order to meet hygienic and environmental standards with respect to air quality, aqueous scrubber systems are in-

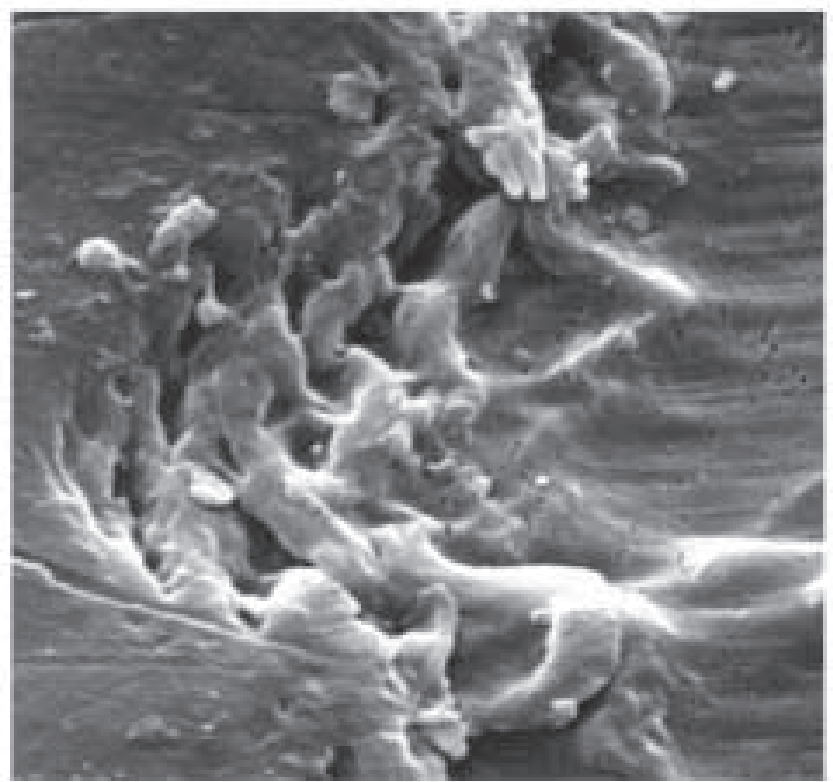

Fig. 20. Polypropylene surface 5000 x magnification showing micro cracks on the surface allowing micro organisms to hide from standard cleaning procedures. Fouling processes likely to start in such micro structures

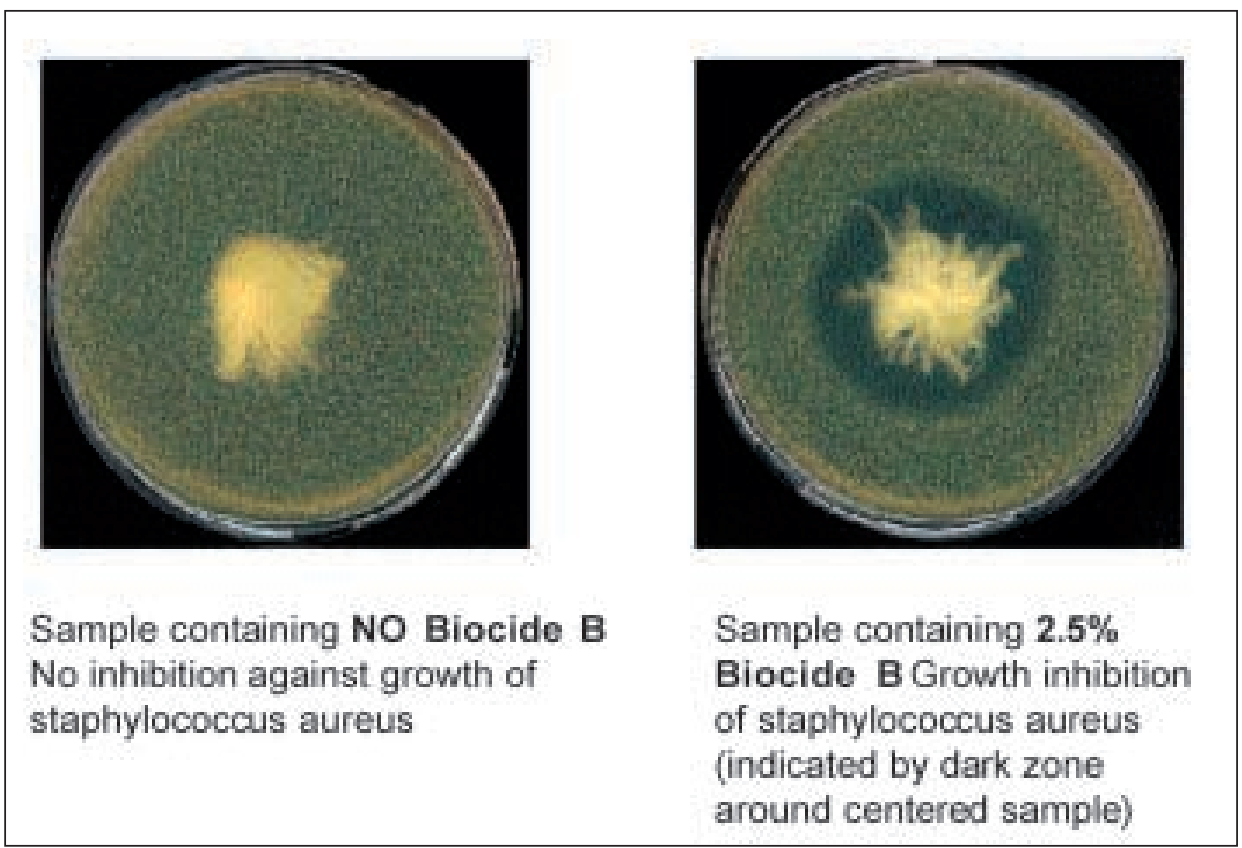

Fig. 21 Agar diffusion test on polypropylene fiber 


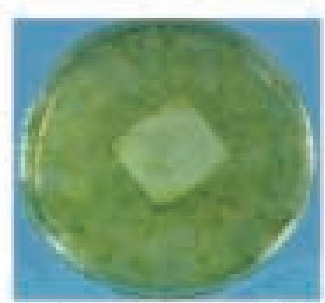

Sample containing NO Biocide A No activity against growth of algae in agar dish test

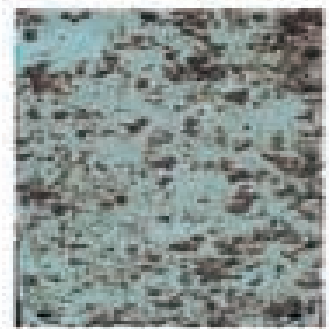

Field test Panel exposed in marina. Panel does not contain any Biocide $\mathrm{A}$

Fig. 22. Agar dish algae growth and field test on PP sheet

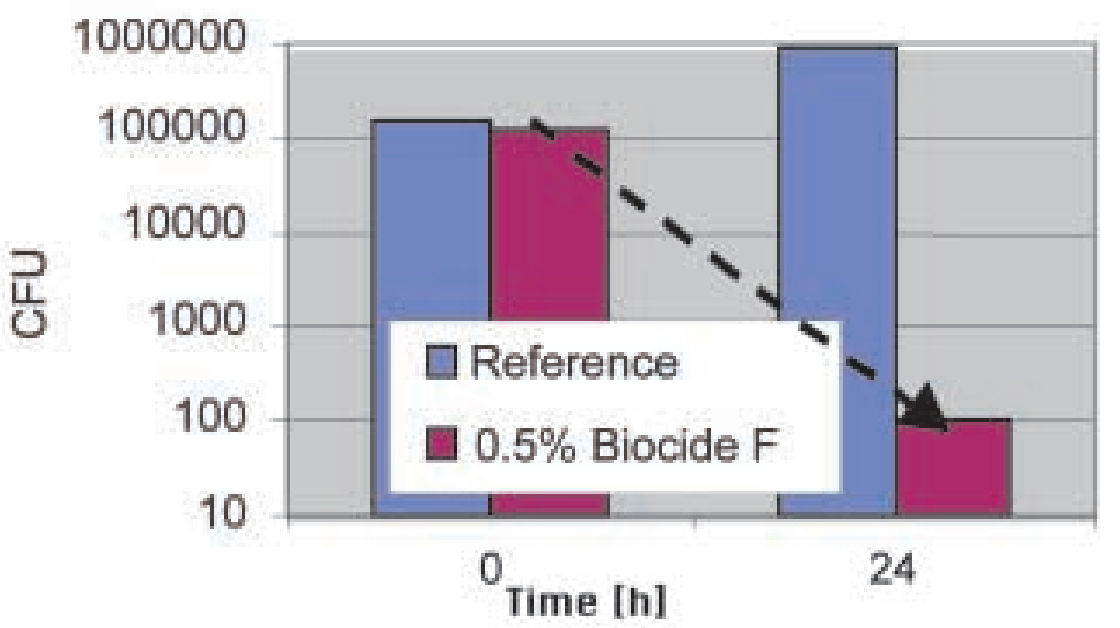

On untreated samples the colony forming units (CFU) of aspergillus niger grow from $120^{\prime} 000$ to about 1 million in $24 \mathrm{~h}$. On samples containing $0.5 \%$ Biocide $F$, a reduction of colony forming units from $120^{\prime} 000$ to 100 in the same period of time was measured demonstrating the high antifungal efficacy of Biocide Fin PP

Fig. 23. Fungal growth on PP plaque stalled. Air from manufacturing units is collected in vent systems and fed to a central scrubbing unit containing a packing material where the used air is purified over a countercurrent stream of water (Fig. 24).

In this example the packing material consists of injection-moulded polypropylene structures that are characterized by a high volume-to-surface ratio.

Air coming off chemical manufacturing units naturally contains high levels of volatile organic compounds (VOC) making air purification systems such as scrubbers necessary. High loadings of organic nutrients in the aqueous phase provides favorable conditions for microbial growth particularly on the surface of the packing. This consequently leads to development of biomass on the surface of the packing material.

As a result of the growth of organic material on the packing, the entire scrubber system clogs up and air quality deteriorates over time.

In terms of pressure drop across the scrubber it is evident that microbial growth on the packing reduces the overall efficacy considerably to the extent that the packing has to be either cleaned or replaced after three months of operation. When using the antimicrobial packing material the uptime of the scrubber could be extended to more than twelve months with the packing material remaining absolutely clean (Fig. 25).

The inherent value of such a solution includes

- Reduced costs

- Higher operational reliability

- Better scrubber performance

- Reduced risk of violating emission regulations

And there is more. Additional tests have been performed to evaluate whether the use of antimicrobial packing material impacts the air quality with respect to germ counts and indeed it was found that the count was reduced up to ten times.

\section{Pipes and Fittings}

Incorporation of Biocide B into polypropylene pipes and fittings can be an effective answer against legionellas that can develop in warm still water. The efficacy of PP fittings containing Biocide B against legionella was tested in the agar diffusion test (Fig. 26).

Despite the difficulty to quantify the benefit, the effect is very high. Here again understanding the effect and the implications are key in communicating the full value. The first case with the 

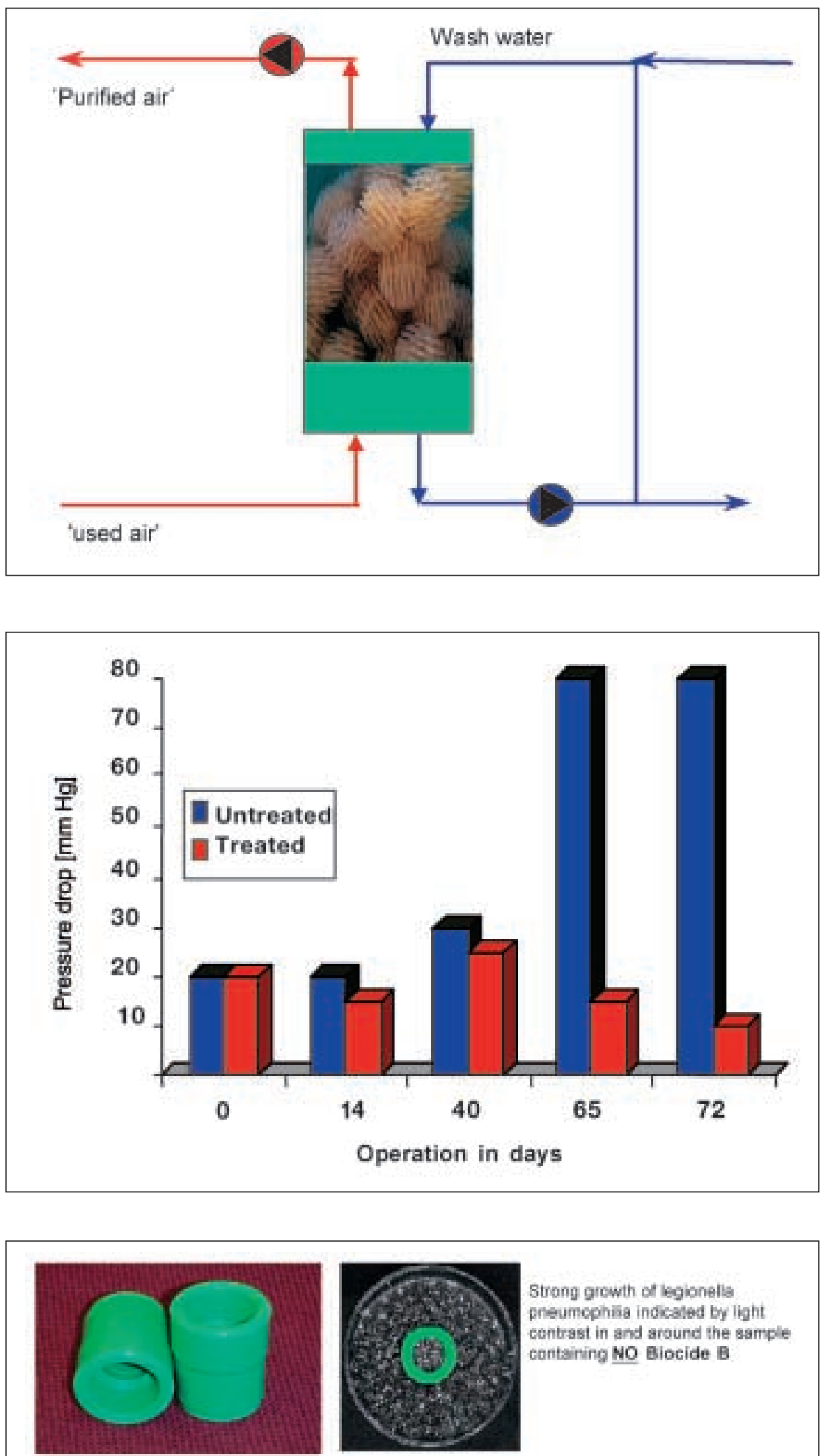

Strong growth of legionella

pneumcohña indicaled by light

contrast in and around the sample

containing NO Biocide B

Polypropylene fitings (abeve) whin and without Biocide B.

Cross sections placed on agar dishes for growth inhibition lest (right).

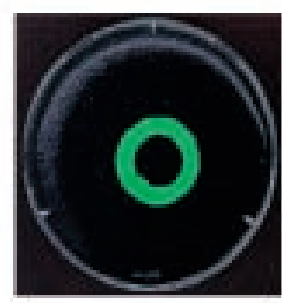

Fig. 24. Wash tower containing polypropylene packing material

Fig. 25. Rapid increase in pressure drop across the column beyond 50 days of operation caused by growth of micro organisms on the packing material made the scrubber inoperable. Treated packing contains $0.3 \%$ of active ingredient
Fig. 26. Antimicrobial test against Legionella pneumophilia ATCC 33152 in PP pipes and fittings 
scrubber illustrated an example where the use of antimicrobial in plastics enhanced productivity. This example shows that the use of an antimicrobial has an impact on hygienic properties. The following example demonstrates how the use of antimicrobial additives can improve comfort, an area where consumers are willing to pay a premium. This example deals with bad odor associated with organic waste.

\section{Waste Containers}

Microorganisms are responsible for the breakdown of organic material, which often leads to bad smells over time. Reduced molecular weight of the decomposition products is responsible for their low volatility. Good examples are decomposition of sweat that naturally does not smell but we all know how bad it can get once bacteria do their work. Another area where development of bad odor is an issue is in waste disposal. Tests were performed where the influence of antimicrobials on the development of malodor of waste containers was investigated. The results were outstanding. The bins containing $5 \%$ Biocide B showed on the head space analysis significant reduction of volatile decomposition products. This observation was confirmed in field tests, which resulted in unanimous attestation 'strong, unbelievable improvement' (Fig. 27).

Applications where the use of biocides add significant value include hospital supplies, waste disposal, air conditioning, sanitary pipes, sporting goods, textiles, shower curtains, toilet seats, boating supplies, mats, pool liners, mobile toilets, crates, coolers, gloves, protective clothing, animal farm supplies, and many more.

Received: March 28, 2002

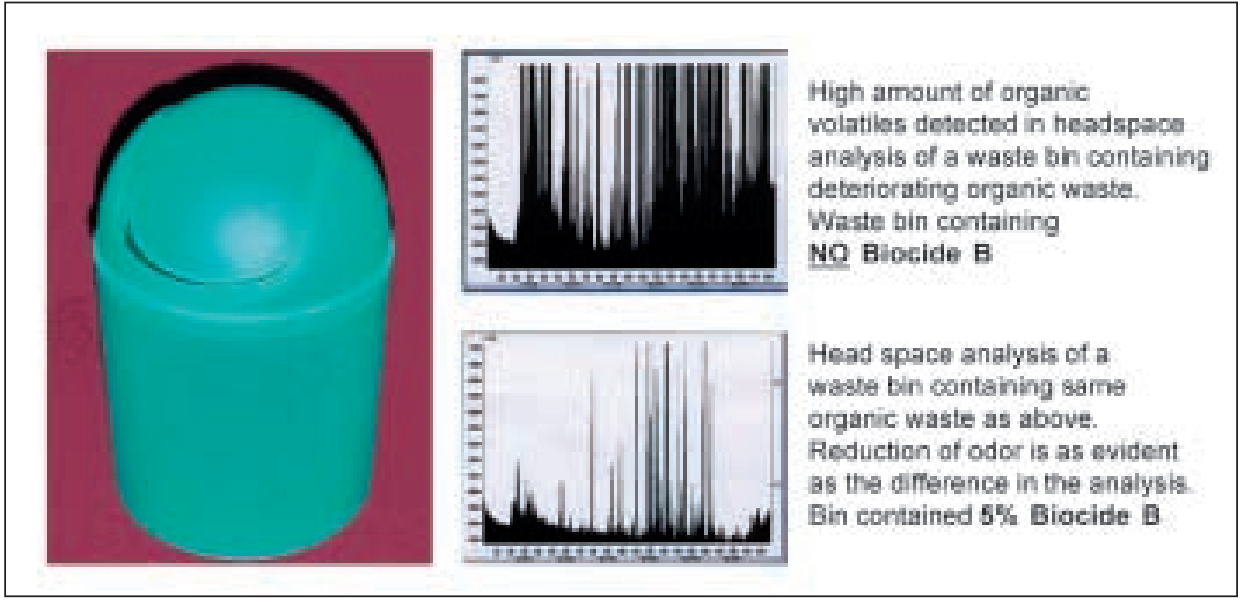

Fig. 27. GC head space analyses of deteriorating waste

[1] H. Zweifel, 'Stabilization of Polymeric Materials', Springer Verlag Berlin, Heidelberg, New York, 1998, p. 81-89.

[2] H. Zweifel, 'Plastics Additives Handbook', 5th Edition, Hauser Publishers Munich, 2001, p. 141-419.

[3] F. Gugumus, N. Lelli, Polymer Degradation and Stability 2001, 72, 407-421.

[4] F. Gugumus, Polymer Degradation and Stability 2002, 75, 295-308.

[5] F. Gugumus, Polymer Degradation and Stability 2002, 75, 309-320.

[6] P. Holbein, 'The High Molecular Hindered Amine Stabilizer for the New Millennium', RAPRA Conference, Addcon World '98, London (UK), November 1998.

[7] N. Lelli, F. Gugumus, Plasticulture 1996, 111, 3-16.

[8] N. Lelli, M. Bonora, 'New Developments in Agrofilms Stabilization', CIPA International Congress for Plastics in Agriculture, Tel Aviv (Israel), March 1997.
[9] S.H. Hamid, 'Handbook of Polymer Degradation', 2nd ed, Marcel Dekker New York, 2000, p. 1-80.

[10] P. Solera, G. Capocci, 'Advances in Stabilization Systems for Paintable and Molded-in Color TPOs', TPOs in Automotive '98, Novi (Mi, USA), October 1998.

[11] A. Lichtblau, Kunststoffe 1996, 86, 955958.

[12] J. Kohler, 'New Developments in Antistatic Agents', Conference of Stability and Ageing Resistance of Rubbers and Plastics, BPR, Brussels (B), November 1995.

[13] M.C. Grob, 'Permanent Antistats: New developments for PO Applications', International Conference on Polyolefins, Polyolefins XI, RETEC, Houston (Texas, USA), February 1999.

[14] 'Biocides keep the bugs off your plastics', in Plastics Technology, February 1998, 45-48.

[15] J. Regös, H.R. Hitz, Zbl. Bat. Hyg. 1 Abt OrigA 1974, 226, 320-401. 
List of Additives

HALS 783

\begin{tabular}{|c|c|}
\hline HPT 1577 & \\
\hline HALS 770 & \\
\hline HALS 791 & HALS $770+$ HALS 944 \\
\hline HALS 494 & HALS $119+$ Co-additives \\
\hline HALS NOR 371 & proprietary NOR-HALS technology \\
\hline HALS 111 & HALS $119+$ HALS 622 \\
\hline HALS 123 & $\mathrm{~N}-\mathrm{OC}_{3} \mathrm{H}_{17}$ \\
\hline Phenolfree FS 042 & $\mathrm{H}_{37} \mathrm{C}_{18}-\mathrm{N}-\mathrm{C}_{18} \mathrm{H}_{37}$ \\
\hline Phenolfiee FS 210 & Phenolfree FS 042 / HALS 119 \\
\hline Phenolfiee FS 410 & Phenolfree FS 042 / HALS 944 \\
\hline Phenolfree FS 811 & Phenolfree FS 042 / HALS 770 / HALS 944 \\
\hline Phenolfree FS 812 & Phenolfree FS 042/ HALS 770 / HALS 944 / BZT 328 \\
\hline HALS XT & Proprietary Blend containing HALS 123 \\
\hline BZT P & \\
\hline BZT 327 & \\
\hline
\end{tabular}

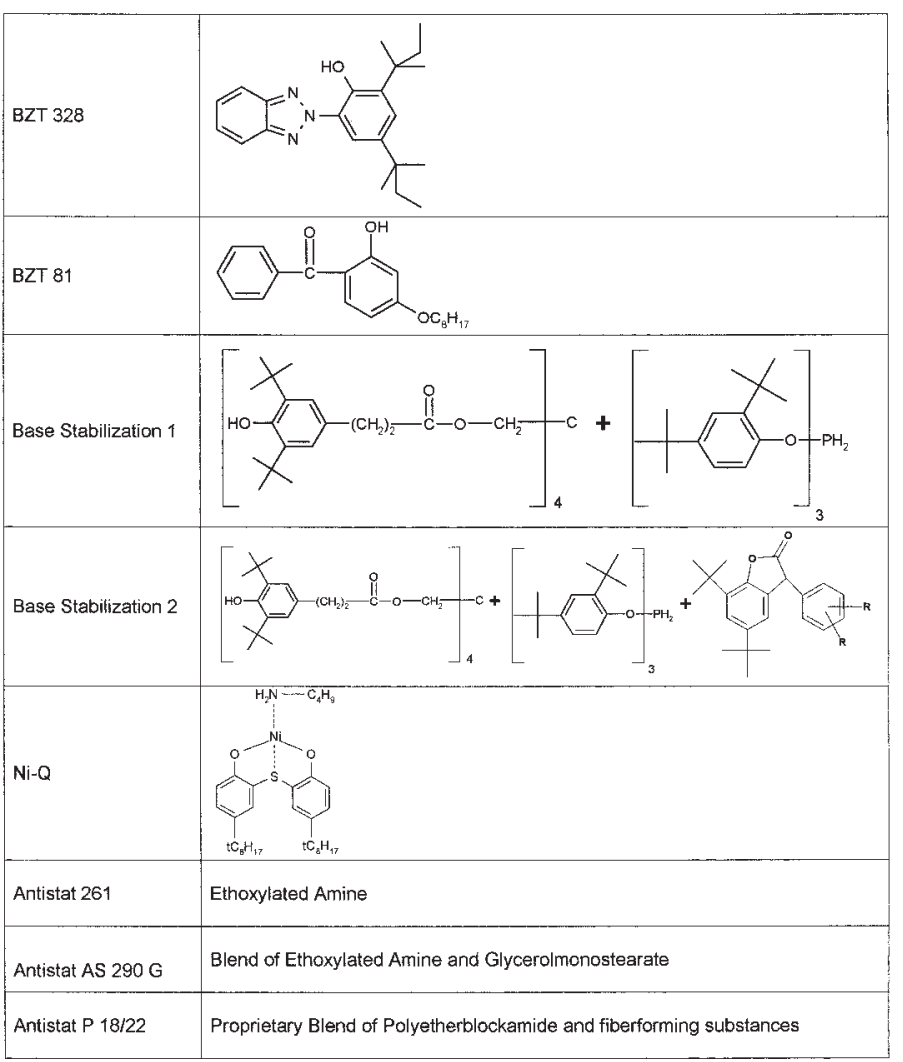

\begin{tabular}{|l|l|l|}
\hline Biocide $B$ & Biocide $\mathrm{F}$ \\
\hline & & \\
\hline
\end{tabular}

